Pasado y Memoria

ISSN: 2386-4745

Núm. 23, 2021, pp. 333-361

https://doi.org/10.14198/PASADO2021.23.14

Estudios

\title{
Las relaciones de España con las monarquías árabes del golfo Pérsico: los gobiernos de Adolfo Suárez y Felipe González
}

\author{
Spain's relationship with the Arab monarchies of \\ the Persian Gulf: The Governments of Adolfo Suárez \\ and Felipe González
}

\author{
Paloma González del Miño \\ Universidad Complutense de Madrid, España \\ pagonzal@ucm.es \\ https://orcid.org/0000-0002-9710-1750 \\ David Hernández Martínez \\ Universidad Autónoma de Madrid, España \\ david.hernandezm@uam.es \\ https://orcid.org/0000-0003-1171-1038
}

Recibido: 16/05/2020

Aceptado: 15/12/2020

Cómo citar este artículo: GONZÁLEZ DEL MIÑO, Paloma, HERNÁNDEZ MARTÍNEZ, David (2021). Las relaciones de España con las monarquías árabes del Golfo Pérsico: los gobiernos de Adolfo Suárez y Felipe González. Pasado y Memoria. Revista de Historia Contemporánea, (23), pp. 333-361, https:// doi.org/10.14198/ PASADO2021.23.14

\section{Resumen}

Las monarquías árabes del golfo Pérsico ocupan una posición preferente en la política exterior de España, debido a su importancia política y económica. La Transición y los primeros Gobiernos democráticos supusieron una profunda renovación de las relaciones internacionales españolas, repercutiendo en la forma de interactuar con las distintas regiones del mundo, incluyendo los regímenes de Oriente Próximo.

C2021 Paloma González del Miño y David Hernández Martínez 
En el período entre 1976-1996, los ejecutivos de Adolfo Suárez y Felipe González pusieron especial interés en fortalecer vínculos con Arabia Saudí, Omán, Emiratos Árabes Unidos, Qatar, Bahréin y Kuwait, constituyendo unas bilateralidades muy estrechas que se han mantenido durante más de cuarenta años. El conjunto de los seis países sigue teniendo una importancia vital para los intereses y objetivos españoles.

Palabras clave: España; Golfo Pérsico; Mundo Árabe; Adolfo Suárez; Felipe González.

\begin{abstract}
The Arab monarchies of the Persian Gulf enjoy a preferential positon in Spain's foreign policy, due to their political and economic relevance. The Transición period and the first democratic governments involved a profound renewal of Spanish international relations, involving ways of interacting with the different regions worldwide, the Middle East regimes included.

In 1976-1996, both Adolfo Suárez and Felipe González focused on strengthening bonds with Saudi Arabia, Oman, United Arab Emirates, Qatar, Bahrain and Kuwait. They established narrow relationships that have been kept up for more than forty years. All those countries still represent an area of vital importance for Spanish interests and objectives.
\end{abstract}

Keywords: Spain; Persian Gulf; Arab World; Adolfo Suárez; Felipe González.

Financiación: Este artículo es resultado de investigaciones realizadas dentro del proyecto: «Crisis y procesos de cambio regional en el norte de África. sus implicaciones para España» (CSO2017-84949-C3-3-P) financiados por el Ministerio de Economía, Industria y Competitividad (MINECO), la Agencia Estatal de Investigación (AEI) y el Fondo Europeo de Desarrollo Regional (FEDER).

\title{
Introducción
}

La Transición y los primeros Gobiernos en democracia de España supusieron un período de enormes cambios políticos, que tuvieron su plasmación en la forma en la que el Estado redefinía su status en las relaciones internacionales. El rasgo principal fue la europeización de la política exterior española, que culminaría con el ingreso en la Comunidad Económica Europea (CEE) en 1986. El giro continental estuvo acompañado por un reforzamiento de la alianza con Estados Unidos (EEUU), tras entrar en la Alianza Atlántica (OTAN) en 1982, y la presencia creciente en América Latina, que encontró su mecanismo institucional con la celebración de las Cumbres Iberoamericanas desde 1991. A estas tres coordenadas principales de política exterior se pueden añadir las relaciones con los países mediterráneos del norte de África y Oriente Medio. 
Desde 1976 hasta 1981, los ejecutivos de Adolfo Suárez y, en menor medida, Leopoldo Calvo Sotelo, intentaron consolidar el régimen democrático interno, prestando menor atención a la acción exterior más allá de profundar en líneas de trabajo heredadas de los últimos estadios del franquismo. Entre 1982 y 1996, fue con los diversos Gobiernos de Felipe González, cuando se produce la gran manifestación internacional de la España democrática, que pretendía superar las limitaciones geoestratégicas heredadas de la dictadura. Se plantea una visión del rol de España en el mundo muy particular, centrado en constituirse en espacio de encuentro entre América y Europa, mundo árabe y Occidente. El golfo Pérsico tuvo una importancia destacada para lograr tal objetivo.

Arabia Saudí, Omán, Emiratos Árabes Unidos (EAU), Qatar, Bahréin y Kuwait se convirtieron en importantes aliados políticos y económicos, sobre todo, debido a la cercanía de la Casa Real de España con los soberanos árabes. La monarquía constitucional instaurada encontró apreciables valederos en las llamadas petromonarquías, gracias, en gran medida, a los preferentes acuerdos comerciales cimentados en el petróleo. La Corona, como nexo de conexión, adoptó un papel promotor de los intereses de España en este espacio regional. No obstante, los regímenes de la península arábiga también tuvieron en el Estado español un socio fiable, que siempre respetó la naturaleza de sus sistemas internos y su papel creciente.

El planteamiento e hipótesis central en el que se asienta el estudio, es que las relaciones con los países del golfo Pérsico también contribuyeron a cimentar el modelo de política exterior normalizada diseñado por España desde la década de 1980. En esta lógica, será a partir de la Transición democrática cuando se supera el tradicional estancamiento de las relaciones diplomáticas, suponiendo la península arábiga una importante plataforma de refuerzo a las cuestiones energéticas y a la diversificación de las relaciones con los Estados del mundo árabe, así como del papel que el Estado español pretendió desempeñar en el mundo en la década de los ochenta y noventa. El trabajo se enmarca en una metodología analítico-descriptiva para aprehender de una forma multidimensional y cronológica todos los factores políticos, económicos, sociales, culturales e históricos que interfieren en las relaciones de España con las monarquías árabes. El desarrollo del análisis permite establecer diferentes fases de la política exterior española hacia el golfo Pérsico, también señalar los actores e instituciones que sobresalen y definen estas bilateralidades, además de poner en contexto la relevancia de los encuentros hispano-árabes en un período crucial para las dos partes. 


\section{Los antecedentes históricos de la política mediterránea y el golfo Pérsico}

La relevancia del mundo árabe en la agenda internacional de España puede llegar a ser categorizado en diferentes niveles de prioridad. En primer término, destacan las bilateralidades con Marruecos, socio preferente del área por intereses económicos, políticos y estratégicos (Hernando de Larramendi y Mañé, 2009: 10-11). En segundo lugar, los regímenes con importantes ligazones económicas como Argelia y las petromonarquías del golfo Pérsico. En el tercer nivel, los países con los que se han mantenido históricamente cordiales relaciones como son Túnez, Egipto, Jordania, Irán o Irak. Finalmente, aquellas áreas donde las relaciones son comparativamente menores que con el resto de Estados árabes como Libia, Líbano, Siria o Yemen.

En la estrategia de España con el mundo árabe, el Magreb ocupa un lugar primigenio en la acción exterior y, concretamente, Marruecos es el socio prioritario. Las relaciones con el Reino alauita son complicadas y complejas (Del Valle, 2007: 23-27), ya que abordan todas las dimensiones posibles: comerciales, políticas, seguridad y defensa, culturales, migraciones, diplomáticas e incluso las relaciones personales entre ambas monarquías. El marco en el que el Estado español opera con su vecino marroquí no tiene ninguna similitud con el resto de países de alrededor o incluso en el ámbito internacional. Las coordenadas con este socio «introducen una complejidad cíclica» dentro de la agenda bilateral, que también conectan con procesos que se desarrollan en la Unión Europea, en el Mediterráneo y en el área intra-magrebí (González del Miño, 2005). Los temas del Sáhara Occidental, mediante un tímido apoyo al Frente Polisario, y las reivindicaciones de Ceuta y Melilla, que se aíslan del ámbito bilateral, suponen uno de los nudos principales de las relaciones que paulatinamente se irán moderando.

La segunda categoría de relaciones se encuadra sobre aquellos países con los que España construye fuertes relaciones económicas y, en menor medida, políticas. Por un lado, la bilateralidad con Argelia, aunque históricamente los vínculos con ese país han sido considerables, será a partir de la década de los ochenta del siglo XX cuando se intensifiquen (Bustos, 2007), principalmente en torno a la cuestión del gas. Por otro, las monarquías árabes del golfo Pérsico, que representan un bloque relevante en las relaciones internacionales españolas en la historia contemporánea. En este sentido, Arabia Saudí tiene un protagonismo excepcional sobre el resto de regímenes de la zona, siendo el eje fundamental en las cuestiones energéticas y securitarias.

Los antecedentes históricos de las relaciones entre España y los países del golfo Pérsico son realmente exiguas, solamente se puede contemplar una vinculación más consolidada y vertebrada superada la segunda mitad del siglo 
$\mathrm{XX}$, coincidiendo con el intento de internacionalización y aperturismo del franquismo y los profundos cambios políticos que tuvieron lugar en todo Oriente Próximo. Estas relaciones se inscriben en el tradicional discurso del régimen, es decir, la manida amistad con el mundo árabe en una retórica diplomática basada en la instrumentalización del mito de al-Andalus como escenario de un pasado común y en el no reconocimiento de Israel. Este período marca el inicio de bilateralidades que crecen paulatinamente hasta alcanzar un nivel elevado en la década de los noventa y principios del XXI. Los factores claves de la evolución progresiva con las distintas petromonarquías se producen entre 1976-1996.

La presencia europea en el golfo Pérsico data desde tiempos griegos y romanos, sin embargo, esta zona sería poco explorada durante muchos siglos, quedando muy limitada al dominio de las sucesivas dinastías persas. Aunque existen dataciones de comerciantes y religiosos de la península ibérica hacia la región a partir del siglo XII (Mehrad, 2012: 23-24), la inferencia española de forma ciertamente institucionalizada comienza a darse a finales del XVI y principios del XVII. La expansión comercial de españoles y portugueses les conduce a reforzar las vías marítimas hacia Asia, entrando en contacto con las dinastías persas safávida y afsárida, que controlaban el interior, y con el antiguo sultanato de Mascate, que se extendía por la costa del mar arábigo.

Las prioridades españolas estuvieron, desde el siglo XVI hasta principios del XX, centradas en otras áreas del mundo, principalmente América y la cuenca sur del Mediterráneo, lo que impidió que los vínculos con el golfo Pérsico fueran más estrechos. El área se convirtió desde finales del XVIII, en centro de disputa por la supremacía marítima entre el Imperio Otomano, la metrópoli británica y los restos del imperio persa de la dinastía Kayar. Reino Unido comenzó a finales de ese mismo siglo a entrar en contacto con tribus y clanes árabes (Peterson, 2008: 280-282), debilitando la influencia de las demás potencias e iniciando un período de protectorados.

La fase transcendental en la historia moderna del golfo Pérsico será tras el final de la Segunda Guerra Mundial. El alcance del conflicto fue reducido en la zona, pero trajo consigo cambios profundos, alentando movimientos de independencia y el nacionalismo árabe, así como los intereses del hegemón estadounidense en el contexto bipolar y el repliegue de los británicos. A partir de la década de los cincuenta es cuando comienza a reactivarse las relaciones entre el Estado español y los regímenes de Oriente Próximo. La monarquía saudí será uno de los puntos de conexión de España con los países árabes y, sobre todo con los del golfo Pérsico a medida que alcanzan su constitución estatal. 


\section{La estrategia franquista hacia el mundo árabe}

El nuevo orden internacional surgido tras el final de la II Guerra Mundial no fue favorable para los intereses de Franco. España quedó excluida del entramado institucional creado al amparo de las Naciones Unidas, en un contexto de polarización entre el eje estadounidense y el bloque soviético, así como la creciente presión de las colonias africanas y asiáticas por romper con el dominio europeo. La perdurabilidad del régimen pasaba en gran medida por la urgencia de buscar nuevos aliados políticos y socios económicos. Este aislamiento internacional empuja las relaciones con los países árabes, que contribuyen al reconocimiento internacional del franquismo e impulsó «la ampliación del ámbito geográfico de la política española hacia Oriente Próximo, hasta entonces terra incognita» (Hernando de Larramendi, 2014: 40).

España pasó por un período de irrelevancia exterior que comienza a cambiar a principios de la década de los cincuenta, teniendo como momentos clave los Pactos de Madrid en septiembre de 1953 con EEUU, que confirman su pertenencia a la esfera noratlántica, y el ingreso en la Organización de Naciones Unidas en 1955, que contó con el apoyo de los países árabes. Comienza un período de paulatina distensión y reactivación a escala internacional, encontrando espacios de cordialidad en los Gobiernos de América Latina, Magreb y Oriente Próximo, pero con fuertes resistencias en Europa y en los márgenes de influencia soviética.

La aproximación entre España y el mundo árabe se produce por la necesidad compartida de respaldo y legitimidad. En primer término, el régimen franquista necesitaba diversificar sus relaciones con el exterior y ampliar el número de potenciales apoyos políticos, que permitieran acabar con la marginación a la que aún intentaban someterle las democracias europeas y otros Estados. El franquismo necesita llenar este vacío internacional con los países árabes y Latinoamérica mediante una política de «sustitución y puente» (Algora, 2007: 16-17), aunque la acción exterior se caracterizara por una falta de visión planificada. En segundo lugar, la mayoría de países árabes se encontraban en un complicado período, marcado por procesos de independencia y movimientos nacionalistas que les obliga a tener que redefinir su papel en el escenario internacional, mientras intentaban consolidar los nacientes sistemas políticos internos.

El inicio del gran viraje en la política exterior de España se da con el ministro de Asuntos Exteriores Alberto Martín-Artajo, que rompe con la neutralidad benévola que supuso la asociación pasada con el eje Berlín-Roma, adaptó el Estado español a las nuevas circunstancias mundiales, pivotando hacia otros núcleos donde la presencia de Madrid no sea vetada. Los esfuerzos fueron 
orientados a superar el cerco impuesto a nivel mundial, mejorando la imagen y reconocimiento del régimen. Por un lado, se planteó el resorte anticomunista con la diplomacia estadounidense; por otro, remarcando los lazos históricos con los países latinoamericanos y, finalmente, la proximidad, vínculos culturales y concordancia de intereses con los regímenes árabes.

No obstante, será con el ministro Fernando María Castiella en la década de los sesenta cuando se produjo «el cambio profundo de la política exterior, de su filosofía inspiradora, de sus objetivos y de su ejecución» (Aldecoa, 1989: 65), siguiendo un modelo continuista por sus sucesores en el Ministerio de Exteriores: Gregorio López-Bravo, Laureano López Rodó y Pedro Cortina Mauri hasta el final de la dictadura. El componente fundamental del acercamiento al mundo árabe recae en la ausencia de factores ideológicos para sostener las bilateralidades. El régimen franquista fue capaz de plantear un campo de acción tan amplio que le permitió entablar vínculos con países de naturaleza política distintas, desde sistemas monárquicos, republicanos, hasta aliados del bloque occidental frente a líderes con fuerte discurso revolucionario y panarabista.

Una cuestión clave para la imagen de España ante las sociedades del Magreb y Oriente Próximo fue el posicionamiento con respecto a la cuestión de Israel y Palestina. Los lazos que mantuvo el Gobierno español con el nazismo provocaron que el naciente Estado israelí tomara una posición de reprobación hacia el régimen franquista, formando parte del núcleo de países que promovieron su exclusión internacional. Estas circunstancias provocaron que desde la diplomacia española se mantuviera una perspectiva favorable a los intereses árabes en los sucesivos conflictos, máxime con el no reconocimiento de Israel que durará hasta 1986 con el Gobierno de Felipe González.

El encuentro con la esfera árabe tuvo una especial intensidad en la década de los cincuenta, en consonancia con la apertura exterior de España y la constitución estatal en el Magreb y Oriente Próximo. Desde 1949, las principales visitas oficiales a Madrid fueron realizadas por líderes como los reyes Abdalá II y Hussein I de Jordania; Faisal II de Irak; Mohammed V de Marruecos; el general Nasser de Egipto, los mandatarios Saúd y Faisal de Arabia Saudí o el Sha de Persia Mohamad Reza Pahlavi. La vehiculización de las relaciones hispano-árabes fue planteada por el régimen franquista inicialmente desde la diplomacia cultural, convirtiendo este factor en el propulsor para vinculaciones políticas y económicas más profundas a posteriori. El Gobierno español promovió la constitución de asociaciones, institutos y tratados de intercambio, que ayudaron a promocionar la imagen de España y del propio régimen entre las poblaciones y élites nacionales (González, 2007: 193-195), aprovechando las ligazones históricas con la idiosincrasia árabe y musulmana. 
Los encuentros de Franco con los dignatarios de Irán, Irak y Arabia Saudí permitieron la entrada en el golfo Pérsico. La cercanía con el Estado iraquí se debilitó tras la revolución de los oficiales de julio de 1958, que terminó derrocando la monarquía Hachemí de Faisal II e instaurando una nueva república de cariz socialista. El nuevo primer ministro y líder militar iraquí, Abdul Karim Qasim, pretendió establecer un régimen independiente del movimiento panarabista de Nasser y muy próximo a la Unión Soviética (Yolcu, 2020: 326328). En este sentido, la estrategia española se centró entonces en fortalecer las relaciones con saudíes y la monarquía del Sha, al compartir como nexo de unión la potencia estadounidense, además de la preocupación por la expansión de la ideología comunista y los movimientos revolucionarios.

Arabia Saudí es uno de los países con los que el régimen franquista desarrolló unas relaciones más fructíferas, que se tradujeron en intenciones de «amistad permanente» como queda patente en el Tratado de Amistad entre España y Arabia Saudí, ratificado en abril de 1962. El rey Saúd visitó España en 1957 y su hermano Faisal en 1966, contribuyendo a expandir las relaciones al ámbito económico. España comenzó a ser uno de los principales demandantes de petróleo saudí, mientras que la industria armamentística nacional encontró un importante comprador en la nación árabe (Eiroa, 2013: 33-34). La estrategia franquista con respecto al régimen de Riad establece las bases de la relación posterior con las demás petromonarquías.

\section{La relevancia internacional de las petromonarquías}

Arabia Saudí canalizó gran parte de los primeros intereses españoles en la zona, debido a la positiva relación directa que se estableció entre príncipes saudís y Gobierno español. En 1961, Kuwait consigue la independencia ante el temor de Reino Unido de verse involucrado en un conflicto por el territorio con Irak. En 1971, los protectorados británicos en el golfo Pérsico terminan finalmente con la independencia de Omán, Qatar, Bahrein y Emiratos Árabes Unidos. Estas circunstancias impiden que el régimen franquista tuviera tiempo para desarrollar relaciones más completas con el resto de petromonarquías, siendo la Casa Saud y el Sha de Persia sus mejores aliados locales.

En la década de los setenta se producen dos acontecimientos que marcan las relaciones de España con las petromonarquías. En primer lugar, la crisis del petróleo de 1973, debido a la decisión de los países árabes de boicotear las exportaciones hacia Occidente por el apoyo a Israel en la guerra de Yom Kippur. A pesar de que desde Madrid se mantuvo una calculada imparcialidad, los efectos de la elevada subida de precios del barril para la economía española fueron devastadores (Sudrià, 2012), obligando a aumentar la atención sobre los 
países productores de crudo. En segundo término, la muerte de Franco en 1975 y el paso a la Transición democrática, condujo al inicio de una nueva política exterior llevada a cabo por José María de Areilza, que se centró en «mejorar la deteriorada imagen de España en Occidente y lograr que la reforma continuista de Arias Navarro sea aceptada por Europa y por Estados Unidos» (Arenal, 2011: 73), quedando en un plano secundario las políticas hacia otras áreas regionales.

Mientras los dirigentes de Omán, Emiratos Árabes Unidos, Qatar, Bahréin y Kuwait focalizaron sus esfuerzos en reforzar su poder doméstico durante la década de los setenta, la corona saudí ya proyectó una política exterior encaminada a consolidarle como líder regional. La figura del rey Faisal, cuyo reinado abarca 1964-1975 (Hernández, 2019: 73-76), fue clave a este respecto, ya que implementó la visión hegemónica saudí para Oriente Próximo, en el marco del saneamiento de la economía y la modernización del país, mientras que en política exterior mantuvo la alianza con Estados Unidos y occidente, la incompatibilidad entre el islamismo y el comunismo y el apoyo a las monarquías y a los regímenes conservadores árabes.

La revolución de Irán en 1979 tiene un alcance drástico en las dinámicas del entorno. Irán y Arabia Saudí habían sido lo que el presidente Nixon bautizó como los «dos pilares gemelos» de la política regional de EEUU (Ulrichsen, 2011: 82-83). El ascenso del régimen de los ayatolás y de Saddam Hussein en Irak provocó que desde las capitales europeas y Washington se prestara mayor atención al golfo Pérsico. La estabilidad y seguridad de las monarquías árabes se convirtió en una prioridad absoluta para las potencias occidentales, fortaleciendo los vínculos políticos, económicos y de defensa con las distintas familias reales de la zona.

La década de los ochenta supone la consolidación internacional de estos seis países del golfo Pérsico, que se presentaron como actores necesarios para la estabilidad regional y la preservación de los intereses occidentales en Oriente Próximo. Arabia Saudí se erigió en el interlocutor preferente del mundo árabe y en el apoyo principal de EEUU para contrarrestar fuerzas revolucionarias. La guerra de Afganistán (1978-1992) que enfrentó a rebeldes muyahidines contra las tropas soviéticas contó con una indispensable intervención saudí, promoviendo el proselitismo religioso que desde la corona de los Saud y otras monarquías se utiliza aún como herramienta de acción exterior.

El siglo XX concluyó en el golfo Pérsico con dos acontecimientos que se mostrarán trascendentales a posteriori. Por un lado, la guerra del Golfo en 1991, que provocó el debilitamiento de la figura de Saddam Hussein y el fortalecimiento de las monarquías árabes en la zona. Por otro, el final de la Guerra Fría y la consolidación de la potencia estadounidense como el gran 
polo hegemónica de las relaciones internacionales, siendo el principal aliado de la mayoría de regímenes árabes.

\section{La acción exterior de Adolfo Suárez (1976-1981)}

\section{Los desafíos internacionales del primer Gobierno democrático}

El liderazgo político de Adolfo Suárez tuvo principalmente su campo de acción en el ámbito interno, focalizando la labor de fortalecer el sistema democrático. En política exterior también se produce un proceso de transición, más lento que en el ámbito doméstico, en la que se suman ciertos rasgos renovadores que pretendían situar al Estado español en el escenario internacional de una forma distinta. El primer responsable del inicio de esta política fue el ministro Marcelino Oreja Aguirre (1976-1980), que partió de la premisa de situar a España en un escenario internacional acorde con sus potencialidades e intereses. Para ello, fue necesario normalizar la acción exterior a nivel bilateral y multilateral, así como ampliar los márgenes de autonomía (Arenal, 1992:392). Este proceso de cambio se prolonga hasta 1986-88, cuando se materializan las últimas grandes innovaciones en este ámbito, y abarca los sucesivos gobiernos de Suarez, Calvo Sotelo y González, renovando en primer lugar la filosofía inspiradora y el diseño y, en segundo lugar, introduciendo reformas en la forma, mediante controles democráticos y dotándola de un cariz más eficaz y realista.

La combinación entre elementos del tardofranquismo y las asunciones democráticas quedaron manifiestas en el giro de universalizar relaciones en consonancia con el cambio democrático (Lemus y Pereira, 2017: 682-683). El Gobierno español mantuvo una línea próxima a EEUU, que quedaría reflejado en los viajes del rey Juan Carlos en 1976 y 1981, los encuentros de Adolfo Suárez con el presidente Carter en 1977, 1979 y 1980 y la visita del mandatario estadounidense a España en 1980. El giro europeísta de la política exterior supuso el inicio del acercamiento a las democracias de Europa occidental. El impulso por diversificar vínculos con el exterior, se comenzó mediante una aproximación hacia nuevas áreas como el sur de Asia o el antiguo bloque soviético.

El único elemento disruptivo de la política exterior en el debate interno de la Transición fue la cuestión del ingreso en la OTAN, que terminaría llevando a cabo el presidente Leopoldo Calvo Sotelo el 29 de mayo de 1982, pocos meses antes de la primera victoria electoral socialista. La Declaración Programática del Gobierno de Suárez de julio de 1977, que luego supondría la base para los Pactos de La Moncloa, remarcaba que el tema sería siempre tratado bajo el amparo del debate parlamentario y con el suficiente consenso político. Las 
principales fuerzas de izquierda estatales -PSOE y PCE- y sectores conservadores -Alianza Popular- se mostraron muy críticas por entonces.

\section{La redefinición de las relaciones con el mudo árabe}

Las relaciones de España con el mundo árabe tras la muerte de Franco estuvieron marcadas por cuatro cuestiones. En primer lugar, el final de la presencia española en el Sáhara Occidental y el conflicto posterior surgido en la zona. En segundo lugar, la cuestión de Palestina y la reconducción de las relaciones con Israel. En tercer lugar, la crisis política abierta en el golfo Pérsico tras la revolución iraní y el ascenso al poder de Saddam Hussein en Irak (1979), junto al conflicto en territorio afgano desde 1978. En último término, la difícil situación de la economía española, que acentuó los profundos desequilibrios de la balanza comercial con respecto a las petromonarquías.

El ministro Marcelino Oreja era consciente de que los desafíos en la región obligaban a plantear una visión más compleja que en la época franquista. El Acuerdo Tripartito de Madrid de noviembre de 1975, firmado por Mauritania, Marruecos y España para el reparto administrativo del Sáhara Occidental, no contó con el reconocimiento de ningún organismo internacional. España decidió retirarse definitivamente del territorio en 1976 (Barreñada, 2017: 278-279), eludiendo sus responsabilidades jurídicas como antigua potencia colonial. El apoyo explícito de la mayoría de dirigentes árabes a la causa del Frente Polisario dejó en una complicada tesitura a las autoridades españolas.

La contienda entre las fuerzas saharauis y Marruecos perduró hasta el alto el fuego de 1991. El Gobierno español asumió la importancia estratégica de las relaciones con el reino marroquí (López, 2013: 76-77). No obstante, necesitaba compensar su posición teniendo en cuenta el respaldo estadounidense a Hassan II, su más estrecho aliado en el Magreb, y la ayuda de Argelia y otros regímenes al Frente Polisario, que comenzaron a su vez a ser importantes socios comerciales para España. Adolfo Suárez puso en práctica la conducta de la potencia ausente, que posterga el problema de su agenda exterior y mantienen una posición equidistante frente a los intereses enfrentados de las partes, aunque progresivamente pivotando hacia priorizar relaciones con Marruecos.

El factor del Sáhara pudiera haberse convertido en un elemento disruptivo con la esfera árabe, sin embargo, la postura oficial española ante el conflicto de Palestina-Israel permitió preservar la confianza de la mayoría de regímenes. Marcelino Oreja decidió continuar con la acción de trabajo planteada por el régimen franquista de impedir la normalización de las relaciones con el Estado israelí, en una posición proárabe que se verifica en el reconocimiento de la Organización para la Liberación de Palestina, la apertura de una oficina de esta 
organización, la visita de Yasser Arafat a Madrid y las votaciones de España a favor de Palestina. El presidente español fue el primer mandatario europeo en recibir oficialmente a Yasser Arafat en septiembre de 1979 (Hernando de Larramendi, 2015: 398-399), dando reconocimiento oficial a la OLP, lo que confirmó la estrecha cercanía del Estado español con los intereses del mundo árabe.

Los acontecimientos en Irak e Irán tuvieron repercusión en la política exterior española. El Gobierno decidió no conceder el asilo al Sha de Persia y su familia a principios de 1979 , puesto que no querían ver afectadas sus relaciones con el nuevo régimen de Teherán. El conflicto irano-iraquí iniciado en 1980 aumentó la inestabilidad en la zona y afectó al comercio marítimo del golfo Pérsico. A finales de la presidencia de Adolfo Suárez, se empezó a producir una revalorización de la imagen de España entre los países europeos y la propia Casa Blanca por su cercanía con las monarquías árabes. La revitalización de la diplomacia española estuvo complementada por la internacionalización de la corona de España. El rey Juan Carlos I realizó numerosos viajes oficiales con el propósito de potenciar la diversificación de las relaciones y conseguir el amparo internacional al emergente sistema democrático. Entre 1976 y 1981, el jefe del Estado español visitó en repetidas ocasiones el golfo Pérsico, reuniéndose con el rey Jálid de Arabia Saudí e iniciando los primeros encuentros al máximo nivel con los monarcas de Kuwait, Bahréin, Qatar y Emiratos Árabes Unidos. La relevancia de la figura del rey Juan Carlos I para los intereses españoles en la zona se explica en gran medida por la singularidad de las relaciones que se vertebraron, ya que el grado de confianza permitió entablar bilateralidades radicadas en la sintonía personal entre casas reales (Powell, 2017). Es en este período cuando el Estado español comienza a ampliar sus actuaciones en el golfo Pérsico, no solamente centrándose en mejorar los vínculos con Riad, sino también hacia el resto de monarquías.

Fue en los primeros años de democracia en España cuando se consolidó el papel del rey Juan Carlos I como un activo importante de la política exterior española. La diplomacia pública de la Casa Real de España pasó a ser una herramienta útil para la estrategia internacional del Gobierno español. El Jefe del Estado comenzó a desempeñar una significativa labor de mediación e interlocución con regiones tan especiales como el mundo árabe (Hernández, 2020: 159-160). No se cuestionó el desempeño diplomático del monarca mientras sirviera para facilitar la presencia de empresas españolas en el golfo Pérsico y asegurara cauces de diálogo político directos entre las jefaturas. En este sentido, la Transición y el Gobierno de Adolfo Suárez estuvieron condicionados por las dificultades económicas de desempleo, inflación, déficit público 
y desaceleración en el crecimiento del PIB. Los acuerdos de exportación de petróleo con Arabia Saudí y demás monarquías árabes conseguidos en ese período llegaron a resultar fundamentales para el reequilibrio macroeconómico (Parón, 2018). La vulnerabilidad y dependencia energética de España a lo largo de la década de los setenta y principios de los ochenta provocaron que las relaciones comerciales con el golfo Pérsico constituyeran un punto central de la agenda exterior e incluso fueran determinantes para la estabilidad interna.

Visitas de personalidades de España a las monarquías árabes (1976-1981)

\begin{tabular}{|c|c|c|c|c|c|c|}
\hline & Arabia Saudí & Omán & EAU & Qatar & Bahréin & Kuwait \\
\hline \multicolumn{7}{|l|}{1976} \\
\hline 1977 & $\begin{array}{l}\text { Visita de } \\
\text { los reyes de } \\
\text { España con } \\
\text { los ministros } \\
\text { de Asuntos } \\
\text { Exteriores } \\
\text { Marcelino } \\
\text { Oreja y el } \\
\text { ministro de } \\
\text { Industria } \\
\text { y Energía } \\
\text { Alberto } \\
\text { Oliart }\end{array}$ & & & & & $\begin{array}{l}\text { Visita del } \\
\text { director } \\
\text { general de } \\
\text { política } \\
\text { financiera } \\
\text { del } \\
\text { ministerio } \\
\text { de } \\
\text { Hacienda } \\
\text { Ignacio de } \\
\text { Satrútegui }\end{array}$ \\
\hline \multicolumn{7}{|l|}{1978} \\
\hline \multicolumn{7}{|l|}{1979} \\
\hline 1980 & $\begin{array}{l}\text { Visita del } \\
\text { presidente } \\
\text { de Adolfo } \\
\text { Suárez con } \\
\text { el ministros } \\
\text { de Asuntos } \\
\text { Exteriores } \\
\text { Marcelino } \\
\text { Oreja y el } \\
\text { ministro de } \\
\text { Comercio } \\
\text { Luis Gámir }\end{array}$ & & & $\begin{array}{l}\text { Visita de } \\
\text { los reyes } \\
\text { de España } \\
\text { con el } \\
\text { ministro } \\
\text { de Asuntos } \\
\text { Exteriores } \\
\text { Pérez- } \\
\text { Llorca }\end{array}$ & & $\begin{array}{l}\text { Visita } \\
\text { de los } \\
\text { reyes de } \\
\text { España y } \\
\text { el ministro } \\
\text { de Asuntos } \\
\text { Exteriores } \\
\text { Pérez- } \\
\text { Llorca }\end{array}$ \\
\hline 1981 & $\begin{array}{l}\text { Visita del } \\
\text { ministro de } \\
\text { Comercio } \\
\text { García Díez }\end{array}$ & & $\begin{array}{l}\text { Visita de } \\
\text { los reyes } \\
\text { de España }\end{array}$ & & $\begin{array}{l}\text { Visita de } \\
\text { los reyes } \\
\text { de España }\end{array}$ & \\
\hline
\end{tabular}

Fuente: BDPEX. Base de Datos integrada de Política Exterior hacia el Mundo Árabe y Musulmán 
Visitas de personalidades de las monarquías árabes a España (1976-1981)

\begin{tabular}{|c|c|c|c|c|c|c|}
\hline & Arabia Saudí & Omán & EAU & Qatar & Bahréin & Kuwait \\
\hline 1976 & & & $\begin{array}{l}\text { Visita del } \\
\text { presidente } \\
\text { de la } \\
\text { cámara de } \\
\text { comercio } \\
\text { Sayud al } \\
\text { Garir }\end{array}$ & & & $\begin{array}{l}\text { Visita } \\
\text { del jeque } \\
\text { Nasser } \\
\text { Sabah }\end{array}$ \\
\hline \multirow[t]{3}{*}{1977} & $\begin{array}{l}\text { Visita del } \\
\text { príncipe Fahd }\end{array}$ & & & & & $\begin{array}{l}\text { Visita del } \\
\text { ministro } \\
\text { del } \\
\text { Petróleo } \\
\text { Abdul } \\
\text { Mutaleb } \\
\text { al-Kazimi }\end{array}$ \\
\hline & $\begin{array}{l}\text { Visita de los } \\
\text { ministros de } \\
\text { Planificación } \\
\text { Hisch N. Nazer } \\
\text { y el ministro } \\
\text { de Industria } \\
\text { e Electricidad } \\
\text { Chazi } \\
\text { al-Sosaibi }\end{array}$ & & & & & \\
\hline & $\begin{array}{l}\text { Visita del } \\
\text { ministro de } \\
\text { Comercio } \\
\text { Soliman } \\
\text { Abdulaziz }\end{array}$ & & & & & \\
\hline 1978 & $\begin{array}{l}\text { Visita del } \\
\text { ministro de } \\
\text { Desarrollo } \\
\text { Urbano } \\
\text { Majedd } \\
\text { Abdulaziz } \\
\end{array}$ & & $\begin{array}{l}\text { Visita de } \\
\text { delegación } \\
\text { diplomática }\end{array}$ & & & $\begin{array}{l}\text { Visita del } \\
\text { alcalde de } \\
\text { Kuwait } \\
\text { Abdul- } \\
\text { Azizi-al- } \\
\text { Adsani }\end{array}$ \\
\hline 1979 & $\begin{array}{l}\text { Visita del } \\
\text { ministro de } \\
\text { Comercio } \\
\text { Soliman } \\
\text { Abdulaziz }\end{array}$ & & & & & \\
\hline 1980 & & & $\begin{array}{l}\text { Visita del } \\
\text { jefe de } \\
\text { protocolo } \\
\text { de EAU Al } \\
\text { Daramki }\end{array}$ & & & \\
\hline
\end{tabular}




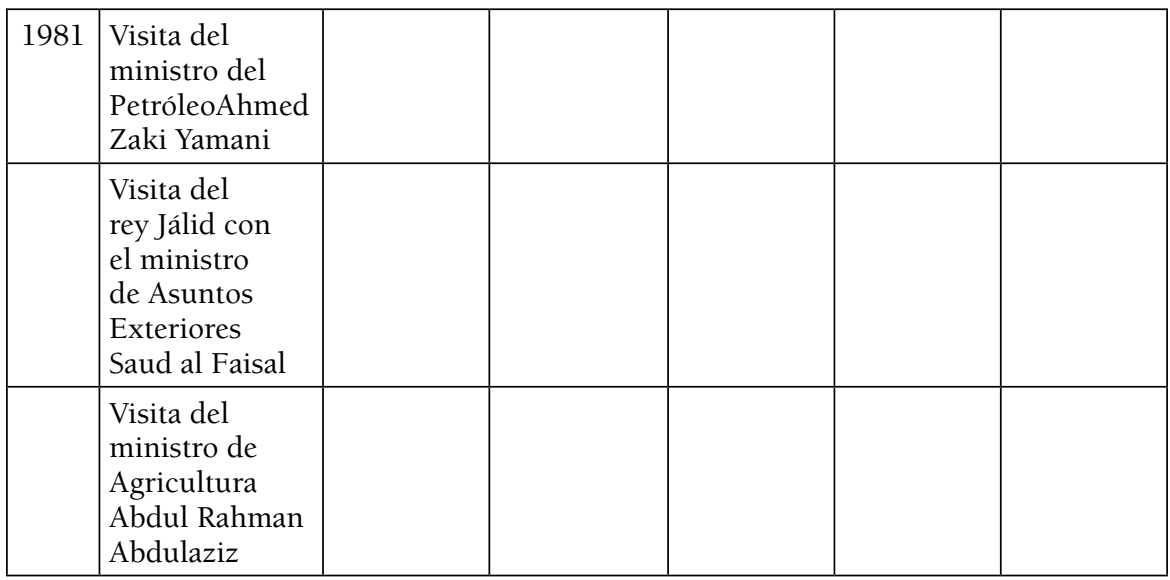

Fuente: BDPEX. Base de Datos integrada de Política Exterior hacia el Mundo Árabe y Musulmán.

\section{La política exterior de los Gobiernos de Felipe González (1982-1996)}

\section{Principios y objetivos internacionales del Gobierno socialista}

Los distintos Gobiernos de Felipe González supusieron una transformación profunda en las dinámicas políticas internas del país, pero también en la forma de proceder y en los objetivos en el proyecto de política exterior. La diferencia clara con los perfiles de Adolfo Suárez y Leopoldo Calvo Sotelo fue el elevado protagonismo internacional que España pretendió desempeñar a lo largo de la década de los ochenta y principios de los noventa con un proyecto de política exterior «que, aunque no excesivamente definido y contrastado y no exento de ambigüedades, especialmente en materia de seguridad y defensa, partía de unos planteamientos más globales y coherentes que los que habían inspirado a los gobiernos centristas» (Arenal, 2011: 193-194). El gran responsable de la renovación en la acción exterior fue el ministro Fernando Morán López (1982-1985), que con posterioridad profundizarían sus homólogos Francisco Fernández Ordóñez (1985-1992), Javier Solana (1992-1995) y Carlos Westendorp (1995-1996).

Los ejecutivos españoles buscaron implementar el cambio y la multidimensionalidad en la política exterior, poniendo en valor la consideración de España como potencia media con unos objetivos e intereses con mayor margen de autonomía. El presidente Felipe González concedió mayor importancia a la cuestión exterior, dándole creciente peso institucional y político, en ocasiones, siendo una materia directamente tutelada desde el departamento internacional 
de La Moncloa (Sanz y Fernández, 2018: 20-21) En este sentido, había una serie de retos a afrontar como eran su rol en el espacio noratlántico, América Latina y Europa, y, por último, promover una acción estratégica y activa con el mundo árabe y no tan focalizada en algunos Estados del Magreb. La finalidad de los Gobiernos de Felipe González para la zona fue vehicular y diseñar la proyección de la política internacional de España dotándola de profundidad, sostenibilidad y globalidad, en el sentido de conferir mayor contenido a las relaciones con Oriente Medio.

En 1980, Fernando Morán, que posteriormente fue ministro de Asuntos Exteriores, ya definió las prioridades de la política española a escala internacional, que guiarían las acciones del Gobierno en la década de los ochenta, centradas en construir lo que él llamo una potencia mundial mediana y una potencia regional de primer orden (Morán, 1980: 20-22). Los grandes logros de la diplomacia española se tradujeron en la entrada en la CCE en 1986, la ratificación de la pertenencia a la OTAN en marzo de ese mismo año. Aún más, el interés por proyectar una imagen de aperturismo y modernidad se plasmó con la celebración de los Juegos Olímpicos de Barcelona y la Exposición Universal de Sevilla de 1992. La preocupación del presidente Felipe González por los asuntos internacionales se tradujo en una agenda exterior más compleja y amplia que la de sus antecesores, que también incluía la reorganización y reforma del Ministerio de Asuntos Exteriores para poner en marcha una política exterior más eficaz y dinámica.

\section{La importancia de las monarquías árabes para España}

La dimensión internacional que Felipe González quiso dar al Estado español y a su propia figura de liderazgo quedó reflejada en varios niveles, entre ellos, hacia el mundo árabe. La formulación del ministro Fernando Morán López de una estrategia compacta y complementaria para distintas regiones (Aránguez, 2018: 157-158), derivó a que las relaciones con el Magreb y Oriente Próximo también fueran incluidas en el paradigma de actuación para un país que buscaba su espacio como potencia media e interlocutor reconocido. España quiso proyectar una amplia imagen de consenso, que pudiera darle una importancia y protagonismo excepcional no repetido en la historia reciente del país.

En marzo de 1983, Felipe González realizó su primera visita oficial al extranjero para visitar al monarca Hassan II sobre una agenda bilateral marcada por cuestiones económicas y para amortiguar las reivindicaciones territoriales de Ceuta y Melilla planteadas por la diplomacia marroquí. Iniciar en Marruecos los viajes internacionales se convierte desde entonces 
en una tradición entre los sucesivos presidentes del Gobierno. La cuestión del Sáhara Occidental comenzó a perder fuerza en la política española, que luego continuará excluyendo de sus prioridades (Vaquer i Fanés, 2007: 122124). Los ministros socialistas plantearon para las bilateralidades con Rabat buscar siempre temas en que los existiera un interés compartido, relegando u obviando los asuntos más controvertidos, iniciando una fase de creciente colaboración comercial.

El ingreso en la CCE en 1986 tiene una doble implicación para las relaciones de España con el mundo árabe. En primer término, el Gobierno español tuvo que adaptar sus marcos comerciales a las exigencias comunitarias, repercutiendo directamente en sus vínculos económicos con los regímenes del Magreb y Oriente Próximo. En segundo lugar, la normalización de relaciones con el Estado de Israel fue una cuestión central para la entrada en la organización (López y Hernando de Larramendi, 2010: 22-23). El ejecutivo de Felipe González tuvo que equilibrar bajo estas circunstancias las presiones recibidas desde Europa y consolidar los intereses con los países árabes. España puso fin a más de cuatro décadas de tensiones con Israel, aunque de manera calculada para no interferir en la buena sintonía con el polo árabe. Felipe González consultó en repetidas ocasiones al rey Fahd de Arabia Saudí la necesidad de que desde Madrid se tuvieran que implementar bilateralidades sólidas con la nación israelí. La monarquía saudí reafirmó su rol como elemento indispensable y de gran influencia en las estrategias de potencias occidentales hacia la zona como evidencia en su relación con el Estado español.

El alcance de reconducir las relaciones con Israel no repercutió en su relación con las monarquías árabes del golfo Pérsico, que fueron quienes lideraban la causa palestina en el ámbito internacional. No obstante, el acercamiento al Estado israelí, a las tesis de política exterior de Ronald Reagan y el ingreso a la OTAN, generó que España también sufriera acciones de carácter yihadista en su territorio. En abril de 1985, se produjo el atentado al restaurante El Descanso, próximo a la base aérea de Torrejón de Ardoz y frecuentado por militares estadounidenses, provocando la muerte de 18 personas y 80 heridos. En julio de 1985, dos bombas en las sedes de la aerolínea British Airways y la jordana Alia en Madrid dejaron un muerto y cerca de una veintena de heridos.

El resultado de los primeros encuentros con Israel y el mantenimiento de las buenas relaciones con los dirigentes árabes fue la consolidación de España como punto de encuentro y diálogo. Felipe González supo aprovechar las circunstancias para reforzar el papel mediador de España (Pardo, 2011: 91-93), que se escenificó en la celebración de la Conferencia de Paz de Madrid 
de 1991, reuniendo a los principales líderes mundiales y representantes de Oriente Próximo. Los vínculos políticos con las monarquías del golfo Pérsico se intensificaron tanto por las conversaciones sobre el conflicto palestino, como el papel asumido por el Gobierno español en la guerra del Golfo de 1991.

El apoyo decidido a la coalición internacional contra la invasión de Kuwait reforzó tanto la confianza de EEUU en su socio español, como la de los regímenes monárquicos árabe. La alta sintonía con los clanes del golfo Pérsico se escenificó en los repetidos viajes del rey Juan Carlos I y presidente Felipe González a lo largo de la década de los ochenta y noventa, así como las visitas oficiales de los dirigentes de aquellos países. El 21 de septiembre de 1992, el rey de España inauguró junto con el príncipe saudí Abdalá el Centro Cultural Islámico de Madrid, conocido comúnmente como la Mezquita de la M-30, uno de los espacios de culto para el islam más grandes de Europa.

La fuerte vinculación con Arabia Saudí y los demás socios locales quedó manifiesta en los estrechos lazos culturales, la sintonía política y la importancia de los factores económicos (Saldaña y Montero, 2012: 162-163). Los Gobiernos de Felipe González pretendieron revertir los desequilibrios en las balanzas comerciales con las petromonarquías, aprovechando la época de crecimiento y desarrollo de España, revertiendo el papel de meros importadores de petróleo para convertirse en uno de los principales canales de inversión extranjera en la península arábiga. El final del siglo XX concluyó en un contexto excepcional de las relaciones para ambos partenaire.

Visitas de personalidades de España a las monarquías árabes (1982-1996)

\begin{tabular}{|c|c|c|c|c|c|c|}
\hline & Arabia Saudí & Omán & EAU & Qatar & Bahréin & Kuwait \\
\hline 1982 & $\begin{array}{l}\text { Visita de } \\
\text { los reyes de } \\
\text { España }\end{array}$ & & & & & \\
\hline & $\begin{array}{l}\text { Visita del } \\
\text { rey de } \\
\text { España por } \\
\text { el funeral } \\
\text { del rey Jálid }\end{array}$ & & & & & \\
\hline 1983 & $\begin{array}{l}\text { Visita del } \\
\text { ministro de } \\
\text { Industria } \\
\text { y Energía } \\
\text { Carlos } \\
\text { Solchaga }\end{array}$ & & & & & \\
\hline
\end{tabular}




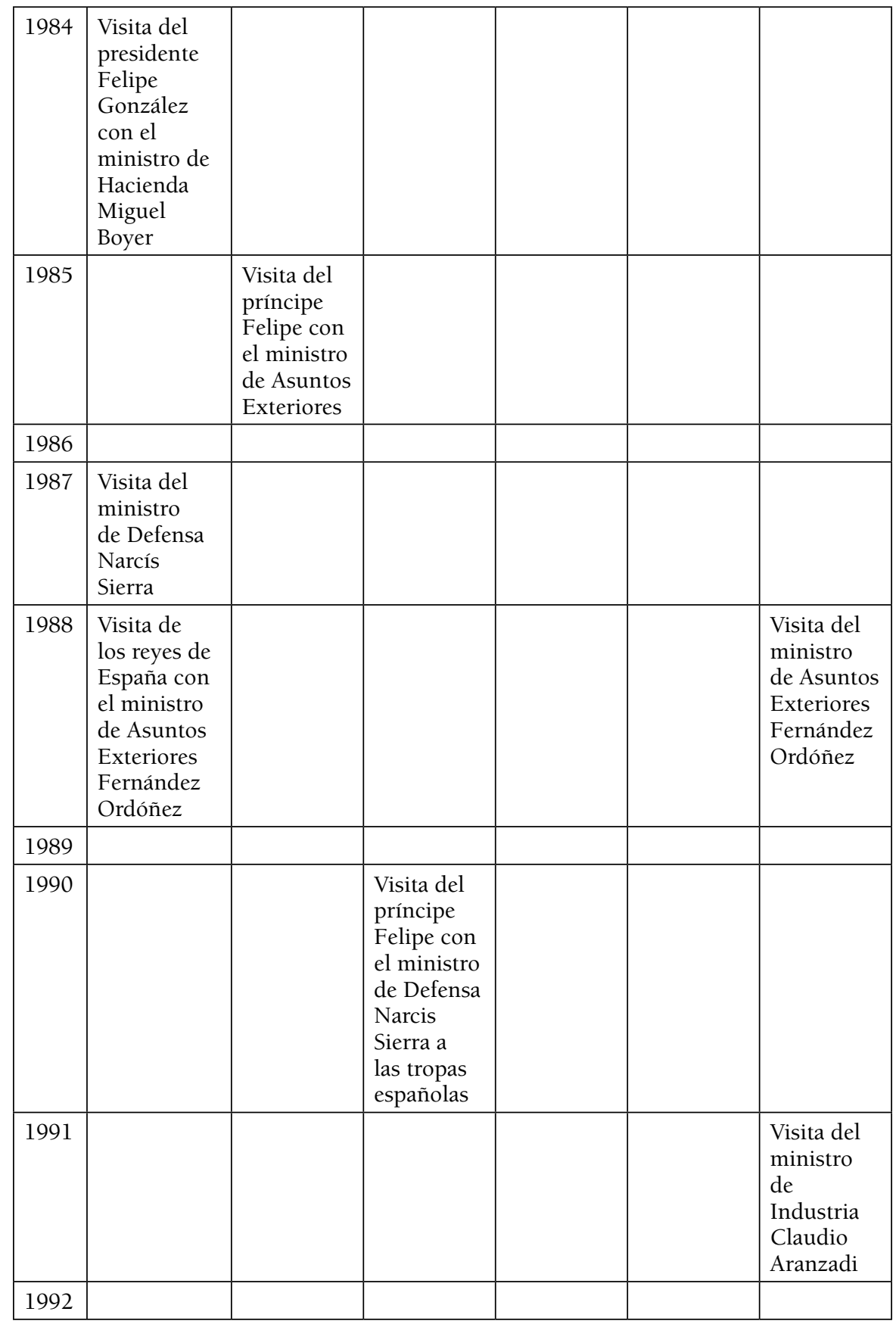

Pasado y Memoria. Revista de Historia Contemporánea, 23, 2021, pp. 333-361 


\begin{tabular}{|c|c|c|c|c|}
\hline 1993 & & & & \\
\hline 1994 & $\begin{array}{l}\text { Visita de } \\
\text { los reyes de } \\
\text { España con } \\
\text { el ministro } \\
\text { de Asuntos } \\
\text { Exteriores } \\
\text { Javier } \\
\text { Solana }\end{array}$ & & & \\
\hline 1995 & $\begin{array}{l}\text { Visita del } \\
\text { ministro } \\
\text { de Defensa } \\
\text { García } \\
\text { Vargas }\end{array}$ & $\begin{array}{l}\text { Visita del } \\
\text { ministro } \\
\text { de Defensa } \\
\text { García } \\
\text { Vargas }\end{array}$ & $\begin{array}{l}\text { Visita del } \\
\text { ministro } \\
\text { de Defensa } \\
\text { García } \\
\text { Vargas }\end{array}$ & $\begin{array}{l}\text { Visita del } \\
\text { ministro } \\
\text { de Defensa } \\
\text { García } \\
\text { Vargas }\end{array}$ \\
\hline 1996 & & $\begin{array}{l}\text { Visita de } \\
\text { la infanta } \\
\text { Cristina }\end{array}$ & & \\
\hline
\end{tabular}

Fuente: BDPEX. Base de Datos integrada de Política Exterior hacia el Mundo Árabe y Musulmán.

Visitas de personalidades de las monarquías árabes a España (1982-1996)

\begin{tabular}{|l|l|l|l|l|l|l|}
\hline & Arabia Saudí & Omán & EAU & Qatar & Bahréin & Kuwait \\
\hline 1982 & & & & & \\
\hline 1983 & $\begin{array}{l}\text { Visita del } \\
\text { ministro } \\
\text { de Defensa } \\
\text { Talal bin } \\
\text { Abdulaziz }\end{array}$ & & & & & \\
\hline 1984 & $\begin{array}{l}\text { Visita del } \\
\text { príncipe } \\
\text { heredero } \\
\text { Abdalá bin } \\
\text { Abdulaziz }\end{array}$ & & & & & \\
\hline 1985 & $\begin{array}{l}\text { Visita del } \\
\text { ministro de } \\
\text { Economía } \\
\text { Soliman bin } \\
\text { Abdulaziz } \\
\text { príncipe } \\
\text { Felipe con } \\
\text { el ministro } \\
\text { de Asuntos } \\
\text { Exteriores }\end{array}$ & & & & & \\
\hline 1986 & $\begin{array}{l}\text { Visita del } \\
\text { Viceministro } \\
\text { del Petróleo } \\
\text { A.H. Taher }\end{array}$ & & & & & \\
\hline
\end{tabular}

Pasado y Memoria. Revista de Historia Contemporánea, 23, 2021, pp. 333-361 


\begin{tabular}{|c|c|c|c|c|c|c|}
\hline 1987 & $\begin{array}{l}\text { Visita del rey } \\
\text { Fahd }\end{array}$ & & \begin{tabular}{|l|} 
Visita del \\
Jefe del \\
Estado \\
mayor de \\
Defensa \\
Muhammad \\
Said Al-Baili \\
\end{tabular} & & & \\
\hline 1988 & $\begin{array}{l}\text { Visita del } \\
\text { príncipe } \\
\text { Salman bin } \\
\text { Abdulaziz }\end{array}$ & & \begin{tabular}{l|} 
Visita del \\
Jefe del \\
Estado \\
mayor de \\
Defensa \\
Muhammad \\
Said Al-Baili
\end{tabular} & & & \\
\hline 1989 & & $\begin{array}{l}\text { Visita del } \\
\text { Sultán } \\
\text { Qaboos bin } \\
\text { Said }\end{array}$ & & & & \\
\hline 1990 & & & & & \begin{tabular}{|l|} 
Visita del \\
ministro de \\
Desarrollo \\
e Industria \\
R.M. Shiraw \\
\end{tabular} & $\begin{array}{l}\text { Visita del } \\
\text { ministro de } \\
\text { Finanza Ali } \\
\text { Jalifa al-Sabah } \\
\text { y el ministro de } \\
\text { Comunicación } \\
\text { Mabibi Jawghar } \\
\text { Kayat }\end{array}$ \\
\hline \multicolumn{7}{|l|}{1991} \\
\hline 1992 & & & & & & $\begin{array}{l}\text { Visita del } \\
\text { ministro de } \\
\text { Información } \\
\text { Bader } \\
\text { al-Yaqoub }\end{array}$ \\
\hline \multirow[t]{2}{*}{1993} & & & $\begin{array}{l}\text { Visita del } \\
\text { sultán Bin } \\
\text { Zayed por } \\
\text { el funeral } \\
\text { de Juan de } \\
\text { Borbón }\end{array}$ & $\begin{array}{l}\text { Visita del } \\
\text { ministro } \\
\text { de Asuntos } \\
\text { Exteriores } \\
\text { Hamad bin } \\
\text { Jasim }\end{array}$ & & $\begin{array}{l}\text { Visita del Jeque } \\
\text { Yaber al-Sabah } \\
\text { por el funeral } \\
\text { de Juan de } \\
\text { Borbón }\end{array}$ \\
\hline & & & & & & $\begin{array}{l}\text { Visita del } \\
\text { ministro de } \\
\text { Información } \\
\text { Saud Nasser } \\
\end{array}$ \\
\hline 1994 & & & & & & $\begin{array}{l}\text { Visita del } \\
\text { ministro de } \\
\text { Defensa Ahmad } \\
\text { al-Sabah }\end{array}$ \\
\hline
\end{tabular}

Pasado y Memoria. Revista de Historia Contemporánea, 23, 2021, pp. 333-361 


\begin{tabular}{|c|c|c|c|}
\hline 1995 & $\begin{array}{l}\text { Visita del } \\
\text { viceministro } \\
\text { de Asuntos } \\
\text { Exteriores } \\
\text { Mamvin } \\
\text { Kurdi }\end{array}$ & $\begin{array}{l}\text { Visita } \\
\text { del alto } \\
\text { diplomático } \\
\text { Yusef bin } \\
\text { Alaui }\end{array}$ & $\begin{array}{l}\text { Visita del } \\
\text { ministro } \\
\text { de Asuntos } \\
\text { Exteriores } \\
\text { Mohammed } \\
\text { ben Mbarek }\end{array}$ \\
\hline & $\begin{array}{l}\text { Visita del } \\
\text { ministro } \\
\text { de Defensa } \\
\text { Abdulaziz } \\
\text { bin Fahd }\end{array}$ & & \\
\hline 1996 & & & \\
\hline
\end{tabular}

Fuente: BDPEX. Base de Datos integrada de Política Exterior hacia el Mundo Árabe y Musulmán.

\section{España en la agenda política de las monarquías árabes}

El desarrollo de la política exterior de los seis Estados árabes tuvo unos rasgos compartidos sobre cuatro premisas centrales: priorizar la seguridad en el golfo Pérsico; reforzar alianza con EEUU; mejorar la cooperación política entre monarquías; y la fuerte dependencia del sistema internacional de sus recursos energéticos que han condicionado las relaciones internacionales. Estas asunciones motivaron que los distintos regímenes mostraron, durante el período de la década de los setenta a los noventa, una preocupación menor por otras cuestiones, reduciendo la proyección de relaciones con las demás potencias occidentales. Sin embargo, Francia y Reino Unido tuvieron un espacio destacado, en menor medida España, mientras que comenzaron a proliferar vínculos comerciales con los emergentes del sureste asiático.

El ascenso formal al poder de Saddam Hussein en Irak y los ayatolás en Irán en 1979 marcaron el inicio de una fase de elevada convulsión e inestabilidad en el golfo Pérsico. La guerra irano-iraquí entre septiembre de 1980 y agosto de 1988 por la soberanía de la región fronteriza de Shatt al-Arab, confirmó a las monarquías árabes la necesidad de reforzar sus estrategias de defensa. El militarismo manifiesto de Teherán y Bagdad fue acompañado de una retórica expansionista. El régimen de los ayatolás reforzó el control administrativo sobre las islas de Abu Musa, Tumb Mayor y Tumb Menor, que eran reclamadas por Emiratos Árabes Unidos, mientras retomó el discurso soberanista sobre el archipiélago emiratí, que siempre las reivindicó como parte de su territorio.

Las fuerzas de Saddam Hussein invadieron en agosto de 1990 Kuwait, provocando una conmoción general entre los países árabes y a escala internacional. La maniobra relámpago obligó a la huida hacia Arabia Saudí del 
emir Yaber III y la pronta anexión del país como una provincia más iraquí. La intervención internacional liderada por EEUU bajo la Operación Tormenta del Desierto, entre enero y febrero de 1991, permitió expulsar a las tropas de Irak y debilitar seriamente sus capacidades militares. Empero, la crisis bélica también puso de relieve las fragilidades de las monarquías árabes, que se encontraban dependientes de la asistencia de potencias extranjeras.

La rivalidad con Irán e Irak condicionó las dinámicas locales, orientando a las monarquías árabes a fortalecer vínculos con Washington, que se consolidó como su principal apoyo internacional. Una década antes, el 23 de enero de 1980, en el discurso del Estado de la Nación, el presidente Jimmy Carter dio a conocer los principios de la llamada doctrina Carter, por la cual EEUU defendería sus intereses en la zona con todos los medios necesarios, incluso militares (Klare, 2007: 32-33). Durante la década de los ochenta y noventa, los estadounidenses reforzaron su presencia, convirtiéndose en el socio político y comercial más importante para las seis dinastías.

La defensa fue asegurada directamente por los estadounidenses, sobre todo, garantizando que los suministros de hidrocarburos no sufrieran ninguna incidencia en su paso por el estrecho de Ormuz. Los dirigentes árabes pudieron centrar sus esfuerzos y recursos en preservar la estabilidad interna y en desarrollar sus estructuras nacionales. A finales del siglo XX, comienzan a implementarse grandes planes nacionales de modernización, que pretendieron superar el estatus primario-exportador de cada una de las economías. Los programas de reformas fueron la respuesta a la crisis de 1986, que manifestó la dependencia del petróleo y la fragilidad de los sistemas productivos.

La necesidad de cooperar entre las seis monarquías ante un conjunto de amenazas comunes dio lugar a la constitución del Consejo de Cooperación para los Estados Árabes del Golfo (CCG), en mayo de 1981. La finalidad fue establecer un espacio común de encuentro, favorecer la asistencia mutua en cuestiones de seguridad y defensa, que dio origen a la creación de la Fuerza militar conjunta del Escudo de la Península, con más de 10 mil efectivos de cada uno de los seis países. No obstante, esta organización regional amplió su contenido a los ámbitos económico y político con el propósito de promover el desarrollo de sus miembros y la actuación coordinada frente a los desafíos en el orden internacional y en el entorno.

La regionalización de la estrategia exterior de los regímenes generó que se prestara especial atención a ciertas problemáticas territoriales, que quedaron pendientes desde los procesos de independencia (Okruhlik y Conge, 1999: 232-234). En primer término, Omán firmó con Emiratos Árabes Unidos (1993) y Arabia Saudí (1990 y 1995) diversos tratados para delimitar oficialmente las 
fronteras. Bahréin y Qatar iniciaron procesos de negociación sobre la soberanía de las Islas Hawar, que terminó resolviéndose en 2001 a estancias de la Corte Internacional de Justicia. Tras el incidente fronterizo en el puesto de control de Al-Khofous entre militares saudíes y qataríes en 1992, los dos países llegaron meses más tarde a un acuerdo de paz que puso fin a las tensiones.

El complejo contexto del golfo Pérsico y las profundas reformas a escala doméstica, impidieron que las petromonarquías tuvieran una agenda internacional más amplia y robusta. No obstante, en la década de los noventa se apreció una intensificación de la acción exterior de los regímenes, comenzando un proceso de diversificación de sus relaciones políticas y comerciales, sobre todo, inducidas a pivotar hacia los polos emergentes de Asia Pacífico (Alterman, 2018: 26-29). La significación de España se enmarca dentro del interés por contar con socios comerciales, pero también con potenciales aliados políticos en un período de enorme transcendencia.

El protagonismo español en las relaciones internacionales de las diferentes monarquías árabes es considerablemente desigual. En un nivel destacado se sitúo el clan de los Saud de Arabia Saudí, asimismo, la familia Al Jalifa en Bahréin y la dinastía Al-Sabah en Kuwait que estrecharon vínculos con la joven democracia europea, sobre todo, a través de las ligazones que surgieron directamente con la familia real española. Omán, Emiratos Árabes Unidos y Qatar entablaron relaciones más tardías, que comenzaron a tener lugar a partir de la década de los noventa, cuando emprende la apertura de sus mercados nacionales y la demanda de inversión extranjera para capitalizar los planes de modernización. Arabia Saudí encontró en España, desde la década de los cincuenta, un preferente socio comercial y político. La relación se intensificó con la llegada del régimen democrático y el protagonismo del rey Juan Carlos I que jugó un papel relevante en la aproximación hacia el mundo árabe (Segal, 1991: 253-254).

Existen varios aspectos en las relaciones que promueven el status preferencial que alcanza España en la zona. En primer término, la historia e influencia cultural árabe en España favoreció una mayor simpatía de las poblaciones locales hacia la presencia española (Jazmati, 2017: 663-664), a diferencia de las reticencias y suspicacias hacia otras potencias occidentales. En segundo lugar, el Gobierno español reforzó su imagen de interlocutor entre el mundo árabe y Europa, estrategia potenciada por los ministros socialistas Móran López y Fernández Ordóñez, un elemento estimado entre las monarquías del golfo Pérsico. Por otro, ambas partes se encontraban inmersas en procesos de modernización y consolidación de sus sistemas internos, que se vio respaldado por la cercana y directa relación entre Casas Reales. En último lugar, la guerra del 
Golfo de 1991 y el decidido compromiso de España con la coalición internacional y sus socios regionales. La decisión del ejecutivo español de participar en la coalición internacional muestra la parcialidad hacia el CCG, desequilibrando sus relaciones con Irak y también indirectamente con el régimen de los ayatolás.

A finales del siglo XX, España logró una posición ventajosa con los seis regímenes, consiguiendo situarse en un nivel elevado de sus agendas internacionales. Si bien durante el franquismo meramente obedeció a una retórica discursiva de amistad y fraternidad con el mundo árabe, con el paso de las décadas fue evolucionando hacia un contenido más profundo, referido a la energía y otros temas comerciales (exportaciones armamentísticas y material de defensa). Fueron los ejecutivos de Felipe González los que contribuyeron de manera decisiva a incorporar cuestiones relativas a Oriente Medio y el Mediterráneo en la agenda de la Unión Europea, siendo un ejemplo la Conferencia de Paz de Madrid de 1991 y el Proceso de Barcelona de 1995.

\section{Conclusión}

Durante el franquismo, la política exterior con los países árabes y, en concreto con las monarquías del golfo Pérsico, fueron más el resultado de una adaptación progresiva a los acontecimientos en esta zona que el fruto de una estrategia previamente diseñada. La llegada de la democracia a España tuvo una repercusión notable en la política exterior del país y en sus objetivos para el escenario internacional. Los grandes cambios se aprecian durante los primeros Gobiernos de Felipe González, con los ministros Morán López y Fernández Ordóñez, que en los ejecutivos de Adolfo Suárez y Leopoldo Calvo Sotelo, ejecutores de líneas más continuistas con los estadios finales del franquismo.

El mundo árabe pareciera restringido a un segundo plano, delimitado sustancialmente a las relaciones con los países del Magreb, sobre todo, Marruecos y Argelia. Sin embargo, las monarquías del golfo Pérsico llegaron a adquirir un espacio notable en las relaciones internacionales de la España democrática. Arabia Saudí, como socio preferente, y los demás miembros del CCG fueron actores destacados para el fortalecimiento de la Transición y la monarquía constitucional, en tanto en cuanto ayudaron al sostenimiento económico en las primeras fases de crisis e inestabilidad. Estas circunstancias explican en gran medida la actitud cercana de los Gobiernos españoles hacia la zona.

Las petromonarquías situaron a España en una posición preferencial de sus agendas internacionales, en gran medida por la estrecha relación que se estableció entre la familia real española y las diferentes dinastías de la región. Estas circunstancias favorecieron la entrada de los intereses españoles en el entorno, 
pero también lo hizo la política planteada por Adolfo Suárez y, sobre todo, Felipe González por ampliar espacios de cooperación en Oriente Próximo, bajo el paradigma de una potencia mediadora. La participación española en la intervención militar de la guerra del Golfo de 1991 reforzó las vinculaciones con este conjunto de países para finales del siglo XX.

El actual estado de las relaciones hispano-árabes está determinado en gran medida por lo acontecido en el período entre 1976-1996. Las monarquías del golfo Pérsico fueron durante los primeros años de la democracia española un apoyo exterior fundamental, sobre todo, en materia económica y en cuanto a respaldo institucional hacia la Casa Real de España. Estas circunstancias derivaron en que desde el Gobierno español y las principales instituciones y fuerzas políticas nacionales siempre se ha tendido a mantener una posición cordial y de proximidad hacia aquellos regímenes. Durante los Gobiernos de Adolfo Suárez y Felipe González se proyectó un enfoque pragmático orientado a preservar la alianza con las monarquías árabes por encima de cualquier tensión o diferencia política. Desde entonces, la estrategia hacia la región del golfo Pérsico ha sido uno de los pocos elementos de continuidad en la acción exterior de los diferentes Gobiernos españoles, independientemente del presidente que ocupara el cargo.

\section{Bibliografía}

ALDECOA, Francisco (1989). Las constantes de la política exterior española. Política y Sociedad, 2, 61-78.

ARÁNGUEZ, José Carlos (2018). La acción exterior del Estado hacia el Magreb (1986-2002): el caso paradigmático de Marruecos. En Juan Carlos PEREIRA, Adela María ALIJA, Misael Arturo LÓPEZ (Eds.). La política exterior de España. De la transición a la consolidación democrática (1986-2001) (157-175). Madrid: La Catarata.

ARENAL, Celestino del (2011). Política Exterior de España y Relaciones con América Latina. Iberoamericanidad, europeización y atlantismo en la política exterior española. Madrid: Fundación Carolina-Siglo XXI.

ARENAL, Celestino del (1992). La posición exterior de España. En R. COTARELO (Comp.). Transición política y consolidación democrática. España (1975-1986) (389-428). Madrid: Centro de Investigaciones Sociológicas.

ALGORA WEBER, María Dolores (2007). España en el Mediterráneo: entre las relaciones hispano-árabes y el reconocimiento del Estado de Israel. Revista CIDOB d'Afers Internacionals, 2007, 79, 15-34. 
ALTERMAN, Jon. B. (2018). China, the United States, and the Middle East. En James REARDON-ANDERSON (Ed.). The Red Star \& the Crescent. China and the Middle East (37-58). London: Oxford University Press.

BARRENADA, Isaías (2017). Western Saharan and Southern Moroccan Sahrawis: national identity and mobilization. En Raquel OJEDA GARCÍA, Irene FERNÁNDEZ-MOLINA, Victoria VEGUILLA (Eds.). Global, regional and local dimensions of Western Sahara's protracted decolonization. When a conflict gets old (277-293) London: Palgrave Macmillan. https://doi. org/10.1057/978-1-349-95035-5_13

BUSTOS, Rafael. (2007). Las relaciones España-Argelia, una mirada desde España. Anuario Internacional CIDOB.: https://www.cidob.org/articulos/ anuario_internacional_cidob/2006/las_relaciones_espana_argelia_una_ mirada_desde_espana

DEL VALLE GÁLVEZ, Alejandro (2007). España-Marruecos: nuevos y viejos paradigmas de una relación en un mundo en mutación. En Juan José SÁNCHEZ SANDOVAL, Abderrahman EL FATHI (Eds.). Relaciones España-Marruecos. Nuevas perspectivas y enfoques (17-46). Cádiz: Servicios de Publicaciones de la Universidad de Cádiz.

EIROA, Matilde (2013). El pasado no es suficiente: temáticas y conflictos en los encuentros de Franco con los líderes árabes y musulmanes. MEAH, Sección Árabe-Islam, 62, 23-46.

GONZÁLEZ DEL MIÑO, Paloma (2005). Las relaciones entre España y Marruecos. Madrid: La Catarata.

GONZÁLEZ, Irene (2007). La hermandad hispano-árabe en la política cultural del franquismo (1936-1956). Anales de Historia Contemporánea, 23, 183-197.

HERNÁNDEZ, David (2020). El reino de Arabia Saudí y la hegemonía de Oriente Medio. Madrid: La Catarata.

HERNÁNDEZ, David (2019). La política exterior de Arabia Saudí en Oriente Medio tras la primavera árabe. Objetivos y estrategias regionales (2011-2016). Tesis Doctoral. Universidad Complutense de Madrid. https://eprints.ucm.es/51661/ HERNANDO DE LARRAMENDI, Miguel (2015). España y el mundo árabe. En J.M. BENEYTO, J.C. PEREIRA (Dirs.). Política exterior de España en los siglos XX y XXI. Volumen II (capítulo 32) (383-412). Madrid: CEU Ediciones.

HERNANDO DE LARRAMENDI, Miguel (2014). Las relaciones exteriores de España con el mundo árabe y musulmán durante el siglo XX. ARWAQ, 9, 39-54. HERNANDO DE LARRAMENDI, Miguel, MAÑÉ, Aurealia (2009). La política exterior española hacia el Magreb. Actores e intereses. Madrid: Editorial Ariel.

JAZTAMI, Ramsi (2017). Arabia Saudí: aliado imprescindible para Europa y España. Documento Opinión, 16. http://www.ieee.es/Galerias/fichero/docs_opinion/2017/DIEEEO16-2017_Arabia_Saudi_RamsiJazmati.pdf 
KLARE, Michael T. (2007). Oil, Iraq and American Foreign Policy. International Journal, 62 (1), 31-42. https://doi.org/10.1177/002070200706200104

LEMUS, Encarnación y PEREIRA, Juan Carlos (2017). Transición y política exterior (1975-1986). En Juan Carlos PEREIRA (Coord.). La política exterior de España. De 1800 hasta hoy (659-683) [2. ${ }^{a}$ ed.]. Madrid: Editorial Ariel.

LÓPEZ GARCÍA, Bernabé (2013). El Sahara y las relaciones hispano-marroquíes. RIPS. Revista de Investigaciones Políticas y Sociológicas, 2 (12), 65-85.

LÓPEZ GARCÍA, Bernabé, HERNANDO DE LARRAMENDI, Miguel (2010). Las relaciones de España con el Mediterráneo y el mundo arabomusulmán. Estado de la cuestión en perspectiva histórica. En Bernabé LÓPEZ GARCÍA, Miguel HERNANDO DE LARRAMENDI (Eds.). España, el Mediterráneo y el mundo arabomusulmán. Diplomacia e Historia. Barcelona: Icaria, Antrazy/IEMed.

MEHRAD, Nazanin (2012). Relaciones diplomáticas entre la Persia safávida y la España de Felipe III: el caso de la primera embajada. Libros de la corte.es, 4, 22-47.

MORÁN, Fernando (1980). Una política exterior para España. Barcelona: Editorial Planeta.

OKRUHLIK, Gwenn, CONGE, Patrick J. (1999). The politics of border disputes: on the Arabian Peninsula. Canada's Journal of Global Policy Analysis. 54(2), 230-248. https://doi.org/10.1177/002070209905400203

PARDO SANZ, Rosa (2011). La política exterior de los gobiernos de Felipe González: ¿un nuevo papel para España en el escenario internacional? Ayer. 84 (4), 73-97.

PARÓN, Camila (2018). Amigos con intereses: España y el mundo árabe. El Orden Mundial. https://elordenmundial.com/amigos-con-intereses-espana-y-elmundo-arabe/

PETERSON, J.E. (2008). Britain and the Gulf: at the periphery of empire. En Lawrence G. POTTER (Ed.). The Persian gulf in history (277-293). London: Palgrave Macmillan. https://doi.org/10.1057/9780230618459_15

POWELL, Charles (2017). El primer embajador de la democracia: Juan Carlos y la proyección exterior de España. Documento de Trabajo. REMCO. Red para el Estudios de las Monarquías Contemporáneas. http://www.spainglobal.com/ files/2017/DT-1-2017-Powell-def.pdf

SALDAÑA MARTÍN, Marta, MONTERO RAMOS, Silvia (2012). Estudios de caso de la política exterior española hacia el Mundo Árabe y Musulmán: países del Golfo. Revista de Estudios Internacionales Mediterráneos (REIM), 12, 161-181. SANZ, Carlos, FERNÁNDEZ, Manuel (2018). Pensar y proponer la política exterior. El departamento internacional de la presidencia del Gobierno: origen y desarrollo (1976-1996). En Juan Carlos PEREIRA, Adela María ALIJA, Misael Arturo LÓPEZ (Eds.). La política exterior de España. De la transición a la consolidación democrática (1986-2001). Madrid: La Catarata. 
SEGAL, Aaron (1991). Spain and the Middle East: a 15- year assessment. Middle East Journal. 2 (45), 250-264.

SUDRIÀ, Carles (2012). El ajuste económico de la transición. El País. 13 Febrero 2012. https://elpais.com/economia/2012/02/10/actualidad/1328871012_734915. html

ULRICHSEN, Kristian C. (2011). Saudi Arabia. En Christopher DAVIDSON (Ed.). Power and politics in the Persian Gulf monarchies. London: Hurst \& Company. VAQUER I FANÉS, Jordi (2007). La política árabe y mediterránea de España. Revista CIDOB d'Afers Internacionals. 79/80,125-144.

YOLCU, Furkan Halit (2020). Building a moderl while debunking another: the rivlary of Arab nationalism between Abd al-Karim Qasim and Gamal Abdel Nasser. Nationalism and Ethnic Politics. 26(3), 319-335. https://doi.org/10.10 80/13537113.2020.1788696 